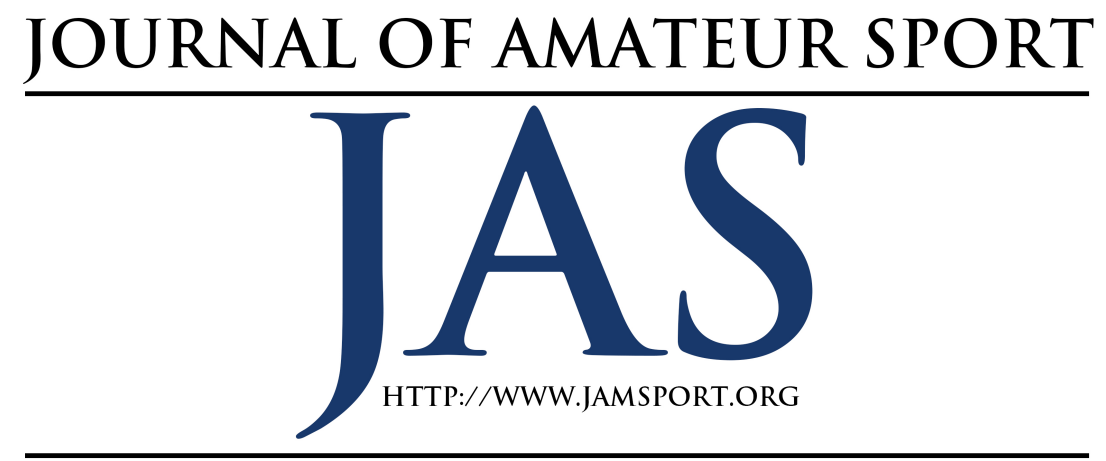

\title{
The Progressive Involvement of Youth in Niche Sport: The Perspective of Youth Participants and Their Parents
}

\author{
Richard J. Buning ${ }^{1} \quad$ Cassie Coble ${ }^{2}$ \\ Shannon Kerwin ${ }^{3}$ \\ ${ }^{1}$ The University of Memphis \\ ${ }^{2}$ Indiana University \\ ${ }^{3}$ Brock University
}

The current study explores youth sport participation by examining the factors perceived to influence youth sampling and specialization in a niche sport. Further, the role of parental influence was examined as a contributing factor to youth sport progression. In-person semi-structured interviews were performed with 18 youth target archery participants and their parents $(\mathrm{N}=28)$. Data analysis revealed target archery may provide a unique context that enhances previously agreed upon perceptions of sampling and specializing within youth sport development. The youth participants' experiences with target archery were found to both confirm and challenge previous conceptions of the deliberate play and practice framework, while parental influence was largely based on opinion and prior experience. Based on these findings, theoretical contributions, suggestions for future research, and practical implications are discussed.

Y

outh physical activity rates in America are on the decline as a result of cultural, social, economic, and familial issues (Browson, Boehmer, \& Luke, 2005). This trend of decreasing physical activity rates mirrors the sport dropout rates that are highest during adolescent years (Dumith,
Gigante, Domingues, \& Kohl, 2011).

Overall, regular sport participation during adolescence has declined by 17 percent between 1992 and 2005 (Berger, O'Reilly, Parent, Seguin, \& Hernandez, 2008).

Such statistics are of concern, as adolescents who participate in sport report higher self-perceptions of health, 
happiness, and belonging (Berger et al., 2008) and are more likely to be active later in life (Pate, Dowda, O’Neil, \& Ward, 2007). Furthermore, youth sport provides a venue for youth to develop a sense of community, which has numerous benefits for both individuals and groups (Warner, Kerwin, \& Walker, 2013).

As a result, it is important to understand the nature of sport participation in youth populations to develop appropriate interventions as well as recruitment and retention strategies. This may be particularly relevant in niche sport as sport managers are looking to increase participation rates through new channels (e.g., non-mainstream sport) and attract a larger population of individuals to their programs. Although the classification of a sport as niche has received some debate (Greenhalgh, Simmons, Hambrick, \& Greenwell, 2011), the commonly agreed upon definition provided by Miloch and Lambrecht (2006) define niche sport as "grassroots sport", that is not mainstream or conventional and does not appeal to a mass audience, while mainstream sport is characterized by broad appeal, an expansive fan base, and widespread media coverage (Greenhalgh et al., 2011). Niche sport is typically considered as fringe, emerging, or second-tier sport in comparison to mainstream counterparts (e.g., baseball, football, basketball; Greenhalgh \&
Greenwell, 2013). The participants and supporters of niche sport are considered to represent a specialty demographic or a sub-segment of general sport consumers (Miloch \& Lambrecht, 2006). Further, niche sport often attracts a smaller number of participants and limited media coverage compared to mainstream sport (Schwarzenberger \& Hyde, 2013).

From a sport spectator perspective, niche sports are associated with different attributes for consumers compared to mainstream sports in that (1) niche sport spectators are able to more closely relate to professionals within their sport, and (2) niche sport spectators see their sport as an inexpensive alternative to mainstream sport (Greenhalgh et al., 2011). However, participation in niche sport is often expensive compared to mainstream sport, as many niche sports require specialized equipment to participate (e.g., cycling, triathlon, rowing, equestrian). Although recent research has been published on niche sport (e.g., Cohen, Brown, \& Peachey, 2012; Warren \& Brownlee, 2013), this work has focused on exploring the unique aspects of marketing and sponsorship in this context, not youth sport progression. However, alternate sporting clubs, such as those in which children can try a number of conventional and niche sports in one place provide unique factors that influence take up and maintenance of participation (Allender, Cowburn, \& Foster, 2006). 
For the purpose of this paper, target archery was deemed a niche sport and served as the research context for the current study. According to the Sporting Goods Manufacturers Association (SGMA, 2012) more than 8 million individuals in the United States above the age of 6 regularly participate in a conventional sport (e.g., baseball, soccer, football) and some sports such as basketball and golf are enjoyed by an excess of 16 million participants annually. However, only 558,000 individuals regularly participate in archery annually (SGMA, 2012), which positions the sport of target archery as a niche sport as it is not mainstream and does not appeal to a mass audience.

Given the unique conditions associated with the niche sport context, it is reasonable to assume that antecedent conditions influencing youth who choose to participate in niche sport would differ as well. According to Côté and Hay (2002), factors influencing entry into a sport may in turn impact future participation and progression through the sport development process. As such, it is important to explore the antecedent conditions to niche sport participation to determine if unique factors are present that alter the progression of youth sport participation. The purpose of this study is to explore youth sport participation in niche sport by examining the factors perceived to influence youth sampling and choice to specialize in the sport of target archery. In particular, the role of parental influence was examined as a contributing factor in determining the level (e.g., continuing sampling [recreation] or specializing and investing [competitive]) of participation youth and adolescents will seek in a niche sport context.

\section{Review of Related Literature}

The Developmental Model of Sport

Participation (DMSP; Côté \& Hay, 2002;

Côté \& Fraser-Thomas, 2007), reproduced in Figure 1, was developed from research with Canadian and Australian athletes and serves as the predominant foundation for understanding: (a) entry into (sampling), (b) participation (specializing), (c) advancement (investment), and (d) withdrawal from (dropout) sport. Accordingly, movement through the DMSP is determined by deliberate play, deliberate practice, and the amount of sport involvement. Côté and colleagues (Côté, 1999; Côté, Baker, \& Abernathy, 2003; Côté \& Hay, 2002) explained deliberate play as sporting activities that provided immediate gratification, were designed to maximize enjoyment, were intrinsically motivating, and provided instant enjoyment. Deliberate practice is described as sporting activities that were motivated by performance goals, required substantial effort, and did not provide an individual with immediate rewards. Deliberate practice also involved highly 
structured activities that were designed explicitly to improve performance (Ericsson, Krampe, \& Tesch-Romer, 1993). Further, Côté, Baker, and Abernathy (2007) outlined specific differences between deliberate play and deliberate practice (see Table 1).

Although a comprehensive model of youth sport progression, the description of involvement in each stage of the DMSP may not fully explore the complexities inherent at each development level for sport participants in niche sport (Côté \& Hay, 2002). Specifically, the sampling years are a period in which parents introduce their child to sport, potentially building interest in such an activity. This period is one in which children are given the opportunity to sample a wide range of sports that aide in the development of fundamental motor skills (Côté \& Hay, 2002). Since niche sport does not appeal to a mass audience and receives relatively less public exposure (Miloch \& Lambrecht, 2006), it may not fit into the traditional definition of sampling as social influences (i.e., parents, peers) are typically the primary factors in determining entry into the sampling stage. Thus, parents and peer groups are less likely to be exposed to and aware of niche sports, so youth are less likely to discover and adopt these sports. Compounding this issue, niche sport (e.g., archery, biathlon, skeleton) may require youth to acquire specific technical skills as well as specialized training (i.e., private coaching) and equipment immediately upon entry in order to participate in a safe manner. Moreover, given that target archery is not a staple within North American society, is typically not part of school curriculum, and is not inherently promoted in mainstream media, participants are often not exposed to target archery, which promotes entrance into the sampling phase of the DMSP.

Within the conventional or mainstream sport context, MacPhail, Gorley, and Kirk (2003) found key features of the sampling stage to be participant involvement in a range of sports, fun and enjoyment, place of competition, fitness and health, deliberate play, and friendships and peer relations. Similar to Bloom's (1985) first stage of learning, the sampling years are crucial to the development of interest in sport and playfulness is a key component to continued participation and success. In addition, fun has been identified as an essential component at this stage (Brustad, 1993; Gould \& Petlichkoff, 1988; Petlichkoff, 1993) and can be generated through experimentation and play (Kleiber, 1981). Youth sport involvement in the sampling years is typically characterized by a high amount of deliberate play, a low amount of deliberate practice, and trying out several different sports (Côté \& Fraser-Thomas, 2007). 
Progressing from the sampling stage, youth often enter the specialization stage, which Baker, Côté, and Deakin (2005) propose occurs when an individual limits their physical activity to two or three sports. Hill and Hansen (1988) relate specialization to the reduction in athletic involvement, specifically indicating that specialization is limiting participation in physical activity to one sport in which the individual trains and competes throughout the year. Côté and colleagues (Abernethy, Côté, \& Baker, 1999; Beamer, Côté, \& Ericsson, 1999; Côté, 1999; Côté et al. 2007; Côté \& FraserThomas, 2007) indicate that specialization is the reduction to one or two specific sports that the individual focuses on and is characterized by an even balance between deliberate play and deliberate practice. Thus, specialization occurs when an individual limits his or her sport involvement to two or three distinct sports, while increasing the amount of time spent performing deliberate practice to that of time spent performing deliberate play. Utilizing the framework proposed by Côté et al. (2007), deliberate play and deliberate practice are discernible through the comparisons depicted in Table 1. Participants and supporters of niche sport represent a specialty demographic or a sub-segment of sport consumers that possess unique characteristics and are thus influenced and motivated to participate for unique reasons (Miloch \&
Lambrecht, 2006). As such, exploring factors associated with sampling and specialization within niche sport progression may help enhance the definitions of each stage within the DMSP.

RQ1: What are the characteristics (e.g., sport involvement, practice, play, coaching) associated with sampling and specialization of youth participants in a niche sport? A variety of factors are known to influence the progression of youth sport development. The expectancy-value model of achievement-related choices (Eccles \& Harold, 1991; Eccles, Wigfield, \& Schiefele, 1998; Fredricks \& Eccles, 2004) addresses the antecedents of an individual's choices and behaviors.

Research related to this model originally examined behaviors in academics and was later extended to test achievementrelated choices in the athletic domain (Eccles \& Harold, 1991). Eccles' model addresses the achievement choices and behaviors an individual engages in and the antecedents associated with these choices, emphasizing the socialpsychological influence on choices and persistence within a task. Specifically, antecedents including (1) the cultural milieu (e.g., cultural stereotypes about sport participation, cultural environment in which a person lives), (2) socialization experiences, (3) a child's aptitudes, and (4) previous experiences influence a child's perceptions and expectations that 
consequently inform their self-beliefs (Eccles, 1993). These self-beliefs in turn influence expectancies and task values which subsequently impact performance and persistence with a task (Eccles et al., 1998), and future task choices (Jacobs \& Eccles, 2000).

According to Eccles' model, an individual's choices are influenced by the relative value of the task and expectations of success for each option (Jacobs \& Eccles, 2000). Individuals engage in a cost-benefit analysis when determining what choices to pursue, as one choice often eliminates other options (Eccles et al., 1998). If the individual perceives the subjective cost to outweigh the values of the activity, the person will discontinue participation in the activity. Conversely, if individuals perceive the activity to be of value or are confident in their abilities, their participation is likely to continue (Eccles \& Harold, 1991). Eccles et al. (1998) expanded the original expectancyvalue model (Eccles \& Harold, 1991) to a more comprehensive model of parental influence, outlining the importance of socializers in the choices that individuals make. Socializers, acting as "providers of experience," "interpreters of experience," and "role models," are said to be the primary influences in an individual's achievement-related choices and behaviors (Eccles \& Harold, 1991). Accordingly, parents, acting as socializing agents, have been shown to influence their child's attitudes (Brustad, 1996) and activity levels in sport (Dempsey, Kimiciek, \& Horn, 1993; Kimiciek \& Horn, 1998).

Examining the role of parents within their child's youth sport development process has received substantial empirical attention in sport psychology research (Côté \& Hay, 2002; MacPhail et al., 2003; MacPhail \& Kirk, 2006). Interestingly, MacPhail and colleagues analyzed both sampling and specializing phases of the development process to determine what role parents may have in the decisions at each level. The findings of the aforementioned studies suggest that parental support and encouragement provide the catalyst for entry and continuance in sport. Further, Côté and Hay (2002) identified parental support as being correlated with a child's enjoyment and enthusiasm with sport participation (Power \& Woolger, 1994) and a parent's willingness and enthusiasm to attend special practices will influence a child's commitment to sport (Monsaas, 1985; Sloboda \& Howe, 1991).

Previous research has established the foundation for understanding the parental influence on youth sport progression. However, the nature of parental influence on youth sport progression may be informed by incorporating theory in relation to Eccles' choice model where an individual's choices are influenced by the relative value of the task and expectations of success for each option (Jacobs \& Eccles, 
2000). Specifically, parental actions as well as attitudes toward and experience with a sport may influence a child's sampling and specialization of a sport through the influence of these attitudes and experiences on the child's value of the task (i.e., niche sport participation) and expectations of success. This may be particularly salient in niche sport where parental opinions and experiences with the sport may be unfounded and limited, respectively, due to the lack of mass exposure depicted in the very definition of niche sport. The general dearth of research on youth niche sport necessitates the investigation of parental influence in this unique context as parents are likely not exposed to niche sports in the same manner as mainstream sport. Thus, as parents likely lack previous exposure and experience with niche sport, the influence they impart onto their child likely differs from mainstream sport.

RQ2: How does parental influence affect youth sport development through continued participation in a niche sport context?

\section{Method}

To understand the complex process of sport progression in a niche sport context, a qualitative case study method involving interviews with children as well as parents was utilized. As described by Yin (2009), a case study is an "empirical inquiry that investigates a contemporary phenomenon within its real-life context; when the boundaries between phenomenon and context are not clearly evident" (p. 23). Further, the case study method allows for an in-depth exploration of a phenomenon (i.e., youth sport progression), while simultaneously allowing the unique nature of the setting to be considered (Stake, 2005). As such, the case study method was deemed most appropriate to serve the purpose of this study as contextual factors specifically impacting the progression through the youth sport development process have been identified in previous literature (Côté et al., 2003). Further, a single case study, rather than a collective case study, was chosen because this site was unique in that it offered this particular niche sport at all three levels of progression (i.e., beginner, intermediate, advanced). With the inclusion of recreational beginners through Olympic level sport in one setting, we believe this one site would provide the most comprehensive understanding of a niche sport context. However, the boundaries between the phenomenon (i.e., progression with sport development) and the context (i.e., different sport settings) may be blurred with niche sport and thus require empirical attention.

Importantly, the findings of case studies are ideal for theory development through falsification testing and the identification of new or deviant cases as they lead to enhanced understanding of 
previously understood phenomenon (Flyvbjerg, 2011). Further, conceptual claims within case studies can be made and transferred to settings that have similar contextual features (Yin, 2009). Thus, an investigation into youth sport progression for a singular niche sport can aid in understanding the progression process for comparable sports. Although the benefits of an ideographic focus were considered, the purpose of this study was to understand the progression of participants within this niche sport to uncover themes that may be transferable to other contexts. As such, a nomothetic methodological approach was chosen and applied to this case study research.

\section{Participants}

As noted within the introduction, target archery was the context for this case study of niche sport participation. More specifically, the case study unit of analysis was a community based target archery program located at a recreation complex in the southeast United States that consisted of approximately 75 youth participants at the time of the study. The corporate sponsored indoor-outdoor archery facility was part of a shared-use community facility ${ }^{1}$ located in a southeastern rural community of approximately 5,000 residents whose median income is slightly above the state

${ }^{1}$ Information regarding the archery program and the facility were obtained from the website and from materials acquired during data collection; however the sources were not directly cited to maintain anonymity. median income (US Census Bureau, 2011) and drew children from the local community as well as surrounding suburban and rural communities. Program participants were recruited through handouts at local schools, archery activities at community events, and through word-of-mouth in the local and surrounding communities. Enrolled participants were able to use equipment provided by the archery program or provide their own equipment.

Participation cost approximately $\$ 50$ per 6 -week course. The site for data collection was selected because the facility offered archery programming for a range of levels and, including beginners who focus on fun and learning to intermediate and advanced classes that were directly associated with the Junior Olympic Archery Development (JOAD) program. Coaches for the program were USA Archery certified Olympic level coaches chosen by the foundation associated with the facility. As such, it was determined that sampling and specialization levels would be present at the site.

The study participants included youth sport participants and their parents who were exclusively recruited from the target archery program. A single embedded case design was adopted as the target archery program represented a "critical" case in testing a well-formulated theory (i.e., DMSP) and the analysis included both youth participants and their parents as 
embedded units (Yin, 2009). In total, the final interview sample included 18 (6 females, 12 males) children ranging in age from 8 to 15 years $(M=11.72, S D=2.05)$. Further, 10 of the parents of the children were interviewed to gain insight into their role or impact on target archery participation. Of the 10 parents, nine identified as mothers and one as a father. In some cases, the parents had more than one child in the target archery program. Two parents declined to partake in the study. Table 2 includes a complete list of the participants (with pseudonyms), their identified sport development level, and age. Five participants were excluded from the final sample as they were identified as participating at the investment level of the DMSP. To serve the purpose of this paper, participants were recruited by sampling or specialization levels.

\section{Interview Guide}

Semi-structured interview guides for both parents and youth participants were generated based on the DMSP to stimulate the collection of pertinent data related to the research questions and to assist in the interview process (Appendix A). The interview guide was deemed most appropriate as a means to collect data as the guide ensured the same basic lines of inquiry are pursued with each interview participant, and allowed the interviewers freedom to probe for specific details regarding the phenomenon that may be particularly relevant to each participant (Patton, 2002). Each interview began with opening comments and warm up questions in order to build rapport with each participant. Next, questions pertaining to each youth participant's perception of his/her archery involvement and the parents' perceptions of their child's archery involvement. Specifically, the interview guide provided several areas of inquiry, including: current sport involvement, previous sport involvement, style of practice, the sport selection process, family support/involvement, coaching, future intentions, and anticipated outcomes. The ordering of questions varied depending on the individual responses from study participants. Supplementary, probing and follow-up questions were asked to gain a thorough understanding of the intricacies of youth sport progression.

\section{Procedure}

Following the consent process outlined through institutional review board (IRB) approval, interviews were scheduled with the youth participants and their parents by a team of two researchers. To ensure rapport was established with each participant as recommended by Irwin and Johnson (2005), the interviews were conducted face-to-face at a private location of the participant's choosing. At the discretion of the parents, youth participants were 
interviewed independently in order to remove any potential parental influence on their child's responses. However, in two cases, the parents opted to be present during their child's interview. Each interview lasted approximately 30 to 60 minutes in duration and was audio recorded. Subsequently, the interviews were transcribed verbatim, which resulted in 392 typed pages.

\section{Data Analysis}

Prior to analysis, the researchers carefully read and reread the interview transcripts to ensure familiarity with the data and participant responses. The data analysis strategy was based on the technique described by Yin (2009) as relying on theoretical propositions. The propositions for the analysis were drawn from the DMSP. The coding process was deductive in nature and entailed relying on an a priori framework provided by the DMSP where open coded text were grouped based on (1) differences between sampling and specialization as described by Côté et al. (2007) and represented in Table 1, and (2) whether a child intended to continue target archery at the recreational or competitive level. It is important to note that none of the youth participants indicated they would discontinue participation in the sport of target archery. This first round of coding was completed by one researcher and an independent research auditor.
Furthermore, for interview data relating to the parents of target archery participants, a similar coding process was used, followed by a slightly modified a priori coding framework. This modified framework was adopted to focus on categorizing codes into themes that resulted in (1) previous experience in archery, (2) involvement in their child's archery, and (3) overall perception of archery. Within this modified framework, the initial read through of the transcripts uncovered common trends with regard to each of these three areas of context. As such, coding categories were created, and specific lines of text were highlighted and pulled into one of these three categorical themes. For example, overall perception of archery was coded with text relating to "it is a safe sport", "family friendly", and words that described the parents" view of the sport.

Following the initial round of coding, two additional researchers (the coauthors who subsequently conducted the interviews) reviewed the coding categories to ensure they concurred with the final coded categories. Further, to ensure trustworthiness and credibility within the collection and interpretation of the data, a number of strategies were adopted (see Shenton, 2004). In terms of trustworthiness between the reader and the researcher, the data was dependable in that the details of collection (including transparency within the interview guide) were clearly outlined for scrutiny 
regarding connection to research questions and findings. Further, confirmability has been established through the use of multiple coders within the coding process. Specifically, the analysis was agreed upon between the primary researchers and a fourth independent researcher who was not included in the data collection or initial analysis. This individual has been trained in qualitative methods and analysis, and has experience working with special populations (e.g., youth). An audit trail was created through the use of NVivo 9.0 computer software to code the data. This process allows any observer to assess the connection between meaning units of text and codes. Finally, in terms of credibility, negatives cases were included in the open coding process where outliers were not eliminated from the discussion of findings analysis as portions of the data differed from the previous theoretical assumptions (Brodsky, 2008). In addition, trustworthiness was enhanced between the researched and the researcher in that the final write up of the findings was presented to the management team of the sport complex in the form of a report. The report was shared with the participants who chose to view the document. However, specific feedback was not solicited directly from the participants.

In order to explore the levels of the DMSP in the target archery context, each participant's progression was determined through the number of sports played and the amount of deliberate play compared to deliberate practice observed, based on delineation of the two terms provided by Côté et al. (2007) as shown in Table 1 and the researchers observations of the programs. It is important to note that the original classification of participants into sampling and specializing during the recruitment stage of data collection was based on definitions of these levels of participation developed from mainstream sport by Côté and colleagues (Côté, 1999; Côté et al. 2007; Côté \& Frasier-Thomas, 2007). However, some study participants discussed characteristics of more than one developmental stage within their respective interview. For example, a participant classified as a sampler for the purpose of data collection may have discussed elements of deliberate practice within their interview. Thus, aspects of these categorizations are discussed in the Findings section.

\section{Findings}

The findings address the factors perceived to influence youth entry into and specialization in a niche sport (i.e., target archery). Specifically, the role of parental influence was found to be a contributing factor in determining the level (i.e., continuing sampling [recreation] or moving on to specialization [competitive]) of participation youth sought in the sport of target archery. Both the sampling and 
specialization phases described by the participants and the role of the parents in influencing youth sport involvement will be discussed in relation to the Expectancy-Value Model of Achievement-Related Choices (Eccles \& Harold, 1991; Eccles et al., 1998; Fredricks \& Eccles, 2004).

\section{Characteristics of Sampling and Specialization in Niche Sport (RQ1) \\ Sampling. For the youth}

participants, the first stage of the DMSP, the sampling years occurred between the ages of 8 and 15 years. The majority of youth sport study participants indicated they were involved in a range of other sports, where fun was a primary motivator for their sports involvement. This was exemplified by Tim, a 12 year old sampler. Specifically, when asked about his entrance into target archery he discussed his involvement in baseball, horseback riding, and football:

My brother's kindergarten, they had their carnival at the very end of the year and [the archery program] had their thing and they set up targets out there and I decided to try it and I really, really liked it... when I was like 7 and 8, I think I played football. But that was, that was only for two seasons and, that, and I was actually playing baseball then too. So that was, it was, I remember one time when we were at the stables, like the one day we had to go to the stables, I had to ride, and then had to go to a football game and then the next day I had to um, ride and then go to the baseball game.

April, a 13 year old participant, also noted that in addition to archery she was involved in several sports. She explained, "right now, I am juggling gymnastics, soccer and archery...my soccer games are on Saturdays and gymnastics is on Thursdays and then archery is on Tuesdays." Archery participants in the sampling phase also indicated fitness, health, and peer relations as important components to their sport involvement. Regarding peer relations, Amy, the mother of Tim, simply puts, "I like being with these people."

Interestingly, using the a priori codes associated with the definition of the sampling phase, the role of deliberate play versus deliberate practice seemed to be blurred by the accounts of the participants. Specifically, the importance of fun within a deliberate, organized setting was noted by several participants, who explained how their coaches structured activities to be enjoyable. Tim explained how practice included aspects of both deliberate practice and deliberate play, noting that they would:

Stretch and everything and then we practice close up to the targets and then we keep getting further and further back and then we usually play a game or two or we will have like a 
competition... [practice is] two hours and it is a lot of fun.

Kimberly, a 10-year-old sampler, also noted the integration of styles, indicating that "all the coaches really are fun to be around because, at the time, they can be very serious and at other times they can have fun."

Additionally, (from Table 1), the idea that sport is "done for its own sake," "adult involvement not required," and "flexibility" seemed to be mixed in participant discussion and thus challenged the definition of deliberate play at this stage. Tim explained his desire to continue in the sport for fun, stating he would "probably do it for fun. I don't think I would really want to become a professional at it." Conversely, five individuals indicated a desire to achieve specific goals, as they indicated a desire to pursue Olympic, professional or scholastic careers in their sport as they progressed through sampling. As Martin, a 10-year-old sampler, noted, he had a desire to be a professional archer as he described here:

Do a lot of practice and have a lot of experience in tournaments and stuff cause when [a professional archer] get[s] sponsored they look at the archery stuff and see how many tournaments [the person has] done and how well [they] do.

Moreover, based on the description of coach involvement and the technique requirements of the sport of target archery, individuals in the sampling stage eluded to the requirement of adult supervision and coaching regardless of where participation took place. As Kimberly explained, "my dad, he helps me a lot because if my sight is not like perfectly right, he would like change it or Coach Rob, he would, like help me with my stance, my posture, and everything" indicating the importance of having someone to aid in participation.

Finally, four individuals commented on aspects of deliberate practice motivated by performance outcomes through learning the proper form and rules, and how important this was to participation in their sport. Kyle, an 11year-old sampler, described:

Coach Steve gives me a lot of tips about my form and what I can do to improve it. Coach Eric does the same. He also helps me if I have any troubles with my bow and so does coach David.

This quotation demonstrates the need for coaches to explain specific rules, form, and equipment needs for youth participants in the sampling phase of this study. As noted in Table 1, deliberate play associated with the sampling phase should not require adult involvement or supervision; this requirement of coach supervision appears to be the norm within the sampling level of this niche sport context.

Specialization. As noted in the Method section, the original classification 
of participants into sampling and specializing during the recruitment stage of data collection was based on definitions of levels of participation developed by Côté and colleagues (Côté, 1999; Côté et al. 2007; Côté \& FrasierThomas, 2007). Specifically, those identified as specializers were involved in an intermediate or advanced level target archery class, which was observed to have a mix of deliberate practice and play. Consequently, participants clearly discussed a balance of deliberate practice and deliberate play with discussion of fun, participating in archery in various settings, carrying out archery in a serious manner, and following explicit rules. To demonstrate the combination of deliberate practice and play, Eric (11 year old, specializer) highlighted, "It is pretty fun... games and stuff. But, I seem to be learning new things. We learn about recurve and shooting targets. We go over a lot of stuff in practice." Further, participants in the specialization level defined increased competition, decreased need for fun during practice, the use of advanced equipment, and the need for advanced knowledge in sport specific skills as key characteristics of their sport experience. As described by Leslie (a 14 year old specializer), the need for advanced equipment occurred very quickly in the specialization of this niche sport:

For the longest time, I didn't have a sight. They said I really needed one, and then we started shooting distance, and I had to get a sight. I like to [shoot] without a sight, but I still have the sight to help [with accuracy]. I have a clicker too ... those things are frustrating. Interestingly, the findings suggest half of the participants identified as being in the specialization phase during data collection were involved in more than two other sports; with one participant identifying six other sports for which he was participating. When asked which sports she participates in regularly, Leslie indicated, "I've done gymnastics. I really liked that. I did ballet....I run. I'm a runner." Justin (15 year old, specializer) further highlighted this point when he stated, "I do tennis at school and I do soccer with friends and, I used to do basketball but, now it is BMX racing." Moreover, indication of a progression toward limiting other sport participation and focusing sport participation on target archery was detailed by only two participants at the specialization level. Thus, it may be concluded that in this niche sport context, specialization is directly linked to specific program factors (e.g., increased competition, decreased fun during practice, advanced equipment, and advanced knowledge in sport specific skills) rather than focusing on the number of sports for which an individual participates. 


\section{Parental Influence on Youth Participation (RQ2) \\ Influence on continued}

recreational participation. Themes

related to influence on individuals

indicating continued recreational

participation in target archery were

related to (1) parental experience in archery and (2) parental opinion of archery. In particular, each parent (but for one exception) of a youth participant who had indicated a preference for continued recreational participation had not been involved in the sport of target archery. Thus, entry into and continuance with the sport of target archery was not directly connected to learned behavior based on following parental involvement or socialization through familial involvement in this context.

With regard to parental opinion of archery, parents described archery as a niche sport that got their child off the couch and was safe. The following quotation demonstrates the opinion of Michelle, the mother of Mark an 11-yearold sampler:

Football scares me. You know, my baby getting hurt. But he sure looks like a football player. If he asks for it, I will say yes but I am not about to suggest it... or encourage it. So I feel like archery is safe.

This implicit promotion of archery for reasons of a means to physical activity in a safe environment may have heightened the youth participants' value for the sport of target archery as a leisure pursuit, which may in turn have influenced their child's decision to continue with the sport of target archery at the recreational level. Further, parents here promoted both recreational and competitive pursuits of their child. However, the youth participants did not indicate a desire to move beyond the recreational level of participation.

Influence on participation at the competitive level. Of the 7 participants that indicated a desire to pursue target archery at the competitive level, all but two were already at the intermediate or advanced level of their archery program. The competitive level was labelled by participants as the desire to compete at the Olympics, as a professional, and/or at the college level. In the case of acknowledging a desire to continue to a competitive level of target archery, there was a mix of whether or not participants had a parent with previous experience in the sport of target archery.

Approximately half of the participants had a mother or father who had participated in archery and the other half did not have a parent or guardian to emulate. In terms of non-participation by parents in the sport of target archery, this was coupled with a lack of previous knowledge of the sport. For instance, Ellen stated,

... it's been a nice environment for him to meet other kids to make some relationships and to learn something 
different, because our family knew nothing about archery when he first began. So for us it's kind of one of those sports where we've had to really learn a lot of the rules and procedures and so on.

In this case, Ellen seemed quite proud of her son for learning a new activity and the family seemed to embrace the notion of learning together.

Remarkably, the parents of those interested in pursuing a competitive level of target archery had mixed opinions of the sport. Specifically, some individuals indicated that target archery was gentlemanly, active, safe and good for confidence, whether others indicated it was "redneck" and boring. Kristin, the mother of Ben and Andy, 12 and 11-yearold specializers, described:

I think a lot of people don't understand it, and I think a lot of people probably think it's boring. It's a lot of standing on a line, shooting arrows at targets.

Despite the mixed parental opinion of archery, all but one youth archery participant who indicated a desire to pursue target archery at the competitive level also discussed the potential of continuing a life-long career in the sport of target archery.

\section{Discussion}

Although youth sport development has received considerable scholarly attention through both empirical and theoretical approaches, this research has typically focused on sporting contexts that appeal to a mass audience and are considered mainstream (Côté, 1999; Côté \& Fraser-Thomas, 2007; Côté \& Hay, 2002; Côté et al., 2003). However, as youth become increasingly less physically active and are more engaged in sedentary activities rather than sport (Berger et al., 2008; Dumith et al., 2011), the traditional understanding of youth sport progression needs to be explored in alternative sport development environments. Thus, the main aim of this study was to examine youth sport progression in a niche sport context (i.e., target archery).

Similar to previous research (MacPhail et al., 2003), the findings depicted the sampling level of the DMSP to be characterized by involvement in several sports and primarily motivated by enjoyment, fitness, health, and social connections. However, the depiction of deliberate play and deliberate practice at the sampling level differed from previous research (cf., Côté et al. 2007).

Specifically, the importance of fun within a deliberate and organized setting was highlighted, and the requirement of adult supervision was detailed as a specific characteristic of sampling within target archery. This is in direct contrast to Côté et al. (2007), who suggested that adult supervision is not required within deliberate play. As such, the findings indicate that deliberate play may have an alternate definition at the sampling level 
of development within the sport of target archery. Further, elements of deliberate practice (i.e., required adult supervision; Côté et al., 2007) may occur earlier in the DMSP and may be more prevalent in the sampling phase of certain sport contexts. Thus, the lines of deliberate practice and play may be blurred due to the use of specialized equipment, the role of parental supervision, and the importance of fun. This blurred line suggests practitioners need to consider the characteristics of the deliberate play and practice framework specific to the sport being managed. Therefore youth sport programs should be organized to allow for practices that focus on the flexible inclusion of parental supervision and elicit excitement and engagement from beginning athletes to assure retention in the sport

The findings also suggest specialization may be directly linked to specific program factors (e.g., increased competition, decreased fun during practice, advanced equipment, advanced knowledge in sport specific skills) rather than focusing on the number of sports for which an individual participates in this niche sport context. In contrast to Côté and colleagues (Abernethy, Côté, \& Baker, 1999; Beamer et al.,1999; Côté, 1999; Côté et al. 2007; Côté \& FraserThomas, 2007) who specifically indicate the reduction to one or two specific sports as a key characteristic of the definition of specialization, the findings associated with these archery participants suggest that an alternate definition with a greater focus on programmatic factors (e.g., increased competition, decreased fun during practice, advanced equipment, and advanced knowledge in sport specific skills) be considered for non-mainstream (i.e., niche) sports. Advanced equipment and sport specific skills appeared to be quite prevalent for these specializer archery participants; two factors that may be specific to target archery and not necessarily other niche sport contexts. For example, target archery requires the use of specialized equipment at both the beginning and advanced stages. In particular, even samplers require equipment that is tailored to each participant to ensure accuracy and safety (e.g., hand grips, sights, stabilizers, draw length/weight).

The role of parental involvement on youth participants who indicated a preference for continued recreational archery participation involved lack of previous experience in archery and a somewhat moderate opinion of archery as a safe form of physical activity. This extends previous literature (Côté, 1999; Côté \& Hay, 2002; Monsaas, 1985; Sloboda \& Howe, 1991) that suggests parental involvement in their child's participation is a factor influencing adolescent entry into the sampling stage of development. Specifically, it would appear that the parents of these archery participants might not act as role models 
or interpreters of experiences for these youth participants as outlined in Eccles and colleagues (Eccles \& Harold, 1991; Eccles et al., 1998; Fredricks \& Eccles, 2004) model of parental influences. Interestingly, similar findings were uncovered for youth participants who described a preference to continue on (or remain) in a competitive level of target archery participation in which parental experience in archery was inconsistent. As such, the influence of cultural milieu, specifically the expectations regarding participation in sport, (Eccles et al., 1998) may impact progression to competitive levels of a niche sport to a greater degree than the presence of parental role models defined by previous sport (archery) experience. Specifically, factors associated with school sport programs, sport related supports, social media influences and social networks may be of interest when exploring influence on sport progression in niche sport contexts (MacPhail et al., 2003). Youth who gravitate to niche sport may attach expectations of value success (as described in Eccles et al., 1998) to social agents outside their familial unit. If niche sport participants are considered unique in and of themselves (Miloch \& Lambrecht, 2006), youth who participate in this context may thrive on being different from those around them. A niche sport may provide a context for which these youth can explore their differences with similar 'others'.
Finally, parental opinion regarding archery for all youth participants (i.e., preference for continued recreational or competitive participation) was fairly neutral in that archery was viewed as a safe form of recreation that was gentlemanly and good for confidence. Given this neutral perception of archery as a sport, the findings support Eccles' theory (Eccles \& Harold, 1991; Eccles et al., 1998; Fredricks \& Eccles, 2004) in that the participants may engage in a cost-benefit analysis when pursuing activity options. Neutral parental opinions in this case support an avenue for physical activity that is a relatively safe and unintimidating environment. The benefits for youth participants in this context are that parents seem to be in support of a sporting activity that provides an option for safe and relatively gentle recreational and competitive pursuits, potentially limiting the parental pressure that often leads to dropout (Gould, Udry, Tuffey, \& Loehr, 1996).

Overall, the findings advance a more thorough understanding of youth sport development by critically analyzing the DMSP in a niche sport context. Despite the contribution to new knowledge discussed, there are limitations to the study that require acknowledgement. First, previous research investigating youth sport progression has typically employed the use of retrospective interviews in order to understand the lifelong outcomes of youth sport 
participation (Côté, 1999; Côté et al., 2003; Côté \& Hay, 2002; Baker, Côté, Abernathy, 2003). Côté et al. (2005) advanced this approach further by proposing a detailed retrospective interview procedure specifically designed to acquire knowledge about the progression process of expert level athletes after they have reached the outcomes identified in the DMSP. However, retrospective approaches using a deliberate practice framework may not be capable of distinguishing expert and non-expert athletes during early stages of development (Baker et al., 2005). Thus, the current study utilized a concurrent interview procedure buttressed by parental interviews in order to better understand an athlete's progression from the sampling stage to the specializing stage. Nonetheless, caution should be taken in assessing intent of participants regarding recreational and competitive pursuits from a concurrent study.

Second, the sampling procedure associated with defining participants at the sampling or specialization level of participation was determined based on the characteristics of these two levels, which were primarily associated with delineations between practice and play (see Côté et al., 2007). It is important to note that our findings suggest this delineation may be skewed within sampling and specialization. Thus, alternative methods of dividing a sample by levels in future studies should be considered. Third, the technical aspects and equipment requirements of target archery may affect progression through the DMSP and the demarcation of deliberate play and deliberate practice. As target archery requires a high level of technical knowledge and instruction during early sport involvement to maintain a safe environment, youth are less likely to partake in unstructured deliberate play associated with target archery. Thus, the findings may be transferred to other contexts with similar features; however, the findings cannot be generalized to all niche sport contexts. Finally, two youth participant interviews were conducted while their parents were present, which may have influenced response bias. Due to IRB protocol, this situation could not be avoided; however, the responses of these two participants were consistent with the other participants in the study. Nevertheless, the limitations discussed here present directions for future research on youth participation in niche sport.

Future research should further investigate youth sport progression in a range of sporting contexts. One such approach could operationalize the concepts in the DMSP in order to gain a broader understanding of the DMSP for a range of sports and participation contexts through quantitative methods. If this approach were undertaken, different sports could be compared and contrasted in an attempt to organize sport 
development programs that more efficiently attract and retain individuals that best fit the intricacies of a particular sport. Further, research could examine the concepts of deliberate practice at all developmental stages of the DMSP to understand the differences by degree or intensity in order to move towards a more thorough understanding of these concepts. Additionally, as youth sport is an avenue to engage parents in the familial relationship and influence socialization into sport for the parents (Dorsch, Smith, \& McDonough, 2009), the impact of youth participation in a niche sport such as target archery on the entire family is important and should be examined more fully. Lastly, continued focus on parents, peers, and social influences in niche sport is needed to understand youth sport development for all.

Youth entry to and decision to specialize in a specific sport may differ based on the sporting context. Thus, practitioners and participants should seek to understand the specific process of sport progression for different sports in their respective setting to more efficiently attract and retain participants. In the target archery context, safety and wellroundedness were praised by parents as sought after features of a sport program. As such, organizing sport programs to emphasize safety and well-roundedness will aid practitioners in attracting and retaining youth who appear to be influenced by these parental opinions. Further, as deliberate practice is infused in the sampling phase of target archery, it is important that coaches and administrators make a distinction between fun and play at the sampling level, and adherence to rules and skill development at the specialization level. If the lines between sampling and specialization become too blurred through the infusion of deliberate practice over deliberate play, youth participants may burnout and remove themselves from archery in the pursuit of alternative activities. This may be particularly relevant to youth who participate in niche sport and who pursue nontraditional activities because they do not feel they fit into conventional or mainstream sport contexts. Here, the characteristics influencing entrance into and continuance in sport must be clearly understood and managed to ensure an individual does not withdraw from sport participation based on a negative costbenefit analysis.

In conclusion, the current study provided an exploratory look into the progressive involvement of youth into niche sport. As a result the study contributes to the established research on youth sport progression by suggesting this process might differ for niche sports as compared to traditional sports as the findings challenged previous delineations of the sampling and specialization stages. Further, the classic understanding of 
deliberate practice and play was

challenged in the unique context of target

archery. Thus, sport managers working in

the youth niche sport should understand

the unique aspects of youth sport

development in niche sport in order to

maximize the effectiveness of their

programs. 


\section{References}

Abernathy, B. Côté, J., \& Baker, J. (1999).

Expert decision-making in sport,

Canberra, Australian: Institute of

Sport Publication.

Allender, S., Cowburn, G., \& Foster, C. (2006). Understanding participation in sport and physical activity among children and adults: A review of qualitative studies. Health Education Research, 21, 826835.

Baker, J., Côté, J., \& Abernathy, B. (2003). Sport specific training, deliberate practice and the development of expertise in team ball sports. Journal of Applied Sport Psychology, 15, 12-25.

Baker, J. \& Côté, J., \& Deakin, J. (2005).

Expertise in ultra-endurance triathletes early sport involvement, training structure, and the theory of deliberate practice, Journal of Applied Sport Psychology, 17, 64-78.

Beamer, M., Côté, J., \& Ericson, K. A. (1999). A comparison between international and provincial level gymnasts in their pursuit of sport expertise. Paper presented at the 10th Annual European Congress of Sport Psychology, Prague, Czech Republic.

Berger, I. E., O'Reilly, Parent, M. M. Sequin, B. Hernandez, T. (2008). Determinants of sports participation among Canadian adolescents. Sport Management Review, 11, 277-307.

Bloom, B. S. (Ed). (1985). Developing Talent in Young People. New York: Ballentine Books.

Brustad, R.J. (1993). Who will go out and play? Parental and psychological influences on children's attraction to physical activity. Pediatric Science, 5, 210-223.

Brustad, R. J. (1996). Attraction to physical activity in urban schoolchildren: Parent socialization and gender influences. Research Quarterly for Exercise and Sport, 61, 316-323.

Brodsky, A. (2008). Negative case analysis. In L. Given (Ed.), The $S A G E$ encyclopedia of qualitative research methods. (p. 553). Thousand Oaks, CA: Sage.

Browson, R. C., Boehmer, T. K., \& Luke, D. A. (2005). Declining rates of physical activity in the United States: what are the contributors? Annual Review of Public Health, 26, 421-43.

Cohen, A., Brown, B., \& Peachey, J. W. (2012). The intersection of pop culture and non-traditional sports: an examination of the niche market of quidditch. International Journal of Sport Management and Marketing, 12, 180-197.

Côté, J. (1999). The influence of the family in the development of talent 
in sport. The Sport Psychologist, 13, 395-417.

Côté, J., Ericsson, K. A., \& Law M. P. (2005). Tracing the development of athletes using retrospective interview methods: A proposed interview and validation procedure for reported information. Journal of Applied Sport Psychology, 17(1), 1-19.

Côté, J., Baker, J., \& Abernethy, B. (2003). From play to practice: A developmental framework for the acquisition of expertise in team sport. In J. Starkes \& K. A. Ericsson (Eds.), The development of elite athletes: Recent advances in research on sport expertise (pp. 89-113). Champaign, IL: Human Kinetics. Côté, J., Baker, J., \& Abernethy, B. (2007). Practice and play in the development of sport expertise. In R. Eklund \& G. Tenenbaum (Eds.), Handbook of sport psychology (3rd ed., pp. 184-202). Hoboken, NJ: Wiley.

Côté, J., \& Fraser-Thomas, J. (2007). Youth involvement in sport. In $\mathrm{P}$. Crocker (Ed.), Sport psychology: A Canadian perspective (pp. 270-298). Toronto: Pearson.

Côté, J., \& Hay, J. (2002). Children's involvement in sport: A developmental perspective. In J. M. Silva \& D. E. Stevens (Eds.), Psychological Foundations of Sport (pp. 484-502). Boston, MA: Ally \& Bacon.
Dempsey, J. M., Kimiecik, J. C., \& Horn, T. S. (1993). Parental influences on children's moderate to vigorous physical activity partcipation: An expectancy-value approach. Pediatric Exercise Science, 5, 151-167.

Dorsch, T. E., Smith, A. L., \& McDonough, M. H. (2009). Parents' experiences of child-toparent socialization in organized youth sport. Journal of Sport \& Exercise Psychology, 31, 444-468.

Dumith, S. C., Gigante, D. P., Domingues, M. R., \& Kohl, H. W. (2011). Physical activity change during adolescence: A systematic review and a pooled analysis. International Journal of Epidemiology, 40, 635-698.

Eccles, J. S. (1993). School and family effects on the ontogeny of children's interests, selfperceptions, and activity choices. In J. E. Jacobs (Ed.), Developmental perspectives on motivation (pp 145208). Lincoln, NE: University of Nebraska Press.

Eccles, J. S., \& Harold, R. (1991). Gender differences in sport involvement: Applying the Eccles' expectancyvalue model. Journal of Applied Sport Psychology, 3, 7-35.

Eccles, J. S., Wigfield, A., \& Schiefele, U. (1998). Motivation to succeed. In W. Damon (Series Ed.) \& N. Eisenberg (Volume Ed.) Handbook 
of child psychology (5th ed., Vol. III, pp. 1017-1095). New York: Wiley.

Ericsson, K. A., Kramp, R., \& TeschRomer, C. (1993). The role of deliberate practice in the acquisition of expert performance. Psychological Review, 100(3), 363-406.

Flyvbjerg, B. (2011). Case study. In N. K. Denzin \& Y. S. Lincoln (Eds.), The Sage handbook of qualitative research (pp. 301-316). Thousand Oaks, CA: Sage.

Fredricks, J. A. \& Eccles, J. S. (2004). Parental influences on youth involvement in sports. In M. Weiss (Ed.), Developmental Sport and Exercise Psychology: A Lifespan

Perspective. Morgantown, WV: Fitness Information Technology. Gould, D., Udry, E., Tuffey, S., \& Loehr, J. (1996). Burnout in competitive junior tennis players: A quantitative psychological assessment. The Sport Psychologist, 10, 322-340.

Gould, D., \& Petlichkoff, L. (1988).

Participation motivation and attrition in young athletes. In F.L. Smoll, R J. Magill, \& M.J. Ash (Eds.), Children in sport (pp.161178). Champaign, IL: Human Kinetics.

Greenhalgh, G. \& Greenwell, T. C. (2013). What's in it for me? An investigation of North American professional niche sport sponsorship objectives. Sport

Marketing Quarterly, 22, 101-112.

Greenhalgh, G. P., Simmons, J. M., Hambrick, M. E., \& Greewell, T. C. (2011). Spectator support: Examining the attributes that differentiate niche from mainstream sport. Sport Marketing Quarterly, 20, 41-52.

Hill, G. M., \& Hansen, G. F. (1988). Specialization in high school athletics: A new trend? Clearing House, 62(1), 40-41.

Irwin, L. G., \& Johnson, J. (2005). Interviewing young children: Explicating our practices and dilemmas. Qualitative Health Research, 15, 821

Jacobs, J. E., \& Eccles, J. S. (2000). Parents, task values, and real-life achievement related choices. In C. Sansone \& J.M. Harackiewicz (Eds.), Intrinsic motivation (pp. 405439). San Diego, CA: Academic Press.

Kimiecik, J. C., \& Horn, T. S. (1998). Parental beliefs and children's moderate-to-vigorous physical activity. Research Quarterly for Exercise and Sport, 69, 163-175.

Kleiber, D.A. (1981). Searching for enjoyment in children's sports. Physical Educator, 38(2), 77-84. MacPhail, A., T. Gorley, \& D. Kirk. (2003). Young people's socialisation into sport: A case 
study of an athletics club. Sport, Education, and Society, 8, 251-267. MacPhail, A., \& Kirk, D. (2006). Young people's socialisation into sport: Experiencing the specializing phase. Leisure Studies, 25, 57-74.

Miloch, K. S., \& Lambrecht, K. W. (2006). Consumer awareness of sponsorship at grassroots sport events. Sport Marketing Quarterly, 15, 147-154.

Monsaas, J. A. (1985). Learning to be a world-class tennis player. In: B. S. Bloom (Ed.), Developing talent in young people (pp. 211-269). New York: Ballantine.

Pate, R. R., Dowda, M., O'Neill, J. R., \& Ward, D. S. (2007). Change in physical activity participation among adolescent girls from 8th to 12th grade. Journal of Physical Activity \& Health, 4(1), 3-16.

Patton, M.Q. (2002). Qualitative Research and Evaluation Methods. Thousand Oaks,

CA: Sage.

Petlichkoff, L. M. (1993). Coaching children: Understanding the motivational process. Sport Science Review, 2, 48-61.

Power, T. G., \& Woolger, C. (1994). Parenting practices and age-group swimming: A correlational study. Research Quarterly for Exercise and Sport, 65(1), 59-66.

Shenton, A. K. (2004). Strategies for ensuring trustworthiness in qualitative research projects.

Education for Information, 22(2), 63-

75.

Schwarzenberger, V. \& Hyde, K. (2013). The role of sports brands in niche sports subcultures. International

Journal of Sports Marketing \& Sponsorship, 15(1), 40-56.

Sporting Goods Manufacturers Association (SGMA). (2012). Sports, fitness \& leisure activities topline participation report. Retrieved from http://www.sfia.org/reports/ 282_Participation-Topline Sloboda, J. A., \& Howe, M. J. A (1991). Biological precursors of musical excellence: An interview study. Psychology of Music, 19, 3-21.

Stake, R. E. (2005). Qualitative case studies. In N. K. Denzin, \& Y.S. Lincoln (Eds.), The Sage bandbook of qualitative research (3rd ed., pp. 443466). Thousand Oaks, CA: Sage. United States Census Bureau, United States Department of Commerce. (2011). 2010 Demographic Profile: [Community] City. Retrieved from http://www.census.gov/popfinder Warren, C., \& Brownlee, E. A. (2013). Brand community integration in a niche sport: A league-wide examination of online and offline involvement in minor league soccer in North America. International Journal of Sport Management and Marketing, 13(3/4), 158-172. 
Warner, S., Kerwin, S., \& Walker, M.

(2013). Examining sense of

community in sport: Developing

the Multidimensional 'SCS' scale.

Journal of Sport Management, 27, 349-

362.

Yin, R. K. (2009). Case study research:

Design and methods (4th ed.).

Thousand Oaks, CA: Sage. 
Journal of Amateur Sport, 2015, 1(1), 52-80

\section{Tables}

Table 1

Comparisons between deliberate play and deliberate practice

\begin{tabular}{ll}
\hline Deliberate Play & \multicolumn{1}{c}{ Deliberate Practice } \\
\hline Done for its own sake & Done to achieve a future goal \\
Enjoyable & Not the most enjoyable \\
Pretend quality & Carried out seriously \\
Interest on the behavior & Interest on outcome of the behavior \\
Flexibility & Explicit rules \\
Adult involvement not required & Adult involvement often required \\
Occurs in various settings & Occurs in specialized facilities \\
\hline
\end{tabular}

Note. Adapted from Côté et al. (2007).

Table 2

Participant \& Parent Pseudonyms and Identified Development Level

\begin{tabular}{llll}
\hline Name & Age & Parent Name & $\begin{array}{l}\text { Development } \\
\text { Level }\end{array}$ \\
\hline Mark & 11 & Michelle & Sampling \\
Chris & 9 & Declined Study & Sampling \\
Kyle & 11 & Declined Study & Sampling \\
Tim & 12 & Amy & Sampling \\
Martin & 10 & James & Sampling \\
April & 13 & Declined Study & Sampling \\
Ann & 11 & Declined Study & Sampling \\
Kimberly & 10 & Denise & Sampling \\
Daniel & 8 & Denise & Sampling \\
Steven & 10 & Lisa & Sampling \\
Rachel & 15 & Lisa & Sampling \\
Eric & 11 & Heather & Specializing \\
Jason & 14 & Susan & Specializing \\
Leslie & 14 & Pauline & Specializing \\
Stacey & 14 & Pauline & Specializing \\
Ben & 12 & Kristin & Specializing \\
Andy & 11 & Kristin & Specializing \\
Justin & 15 & Ellen & Specializing \\
\hline
\end{tabular}


Figures

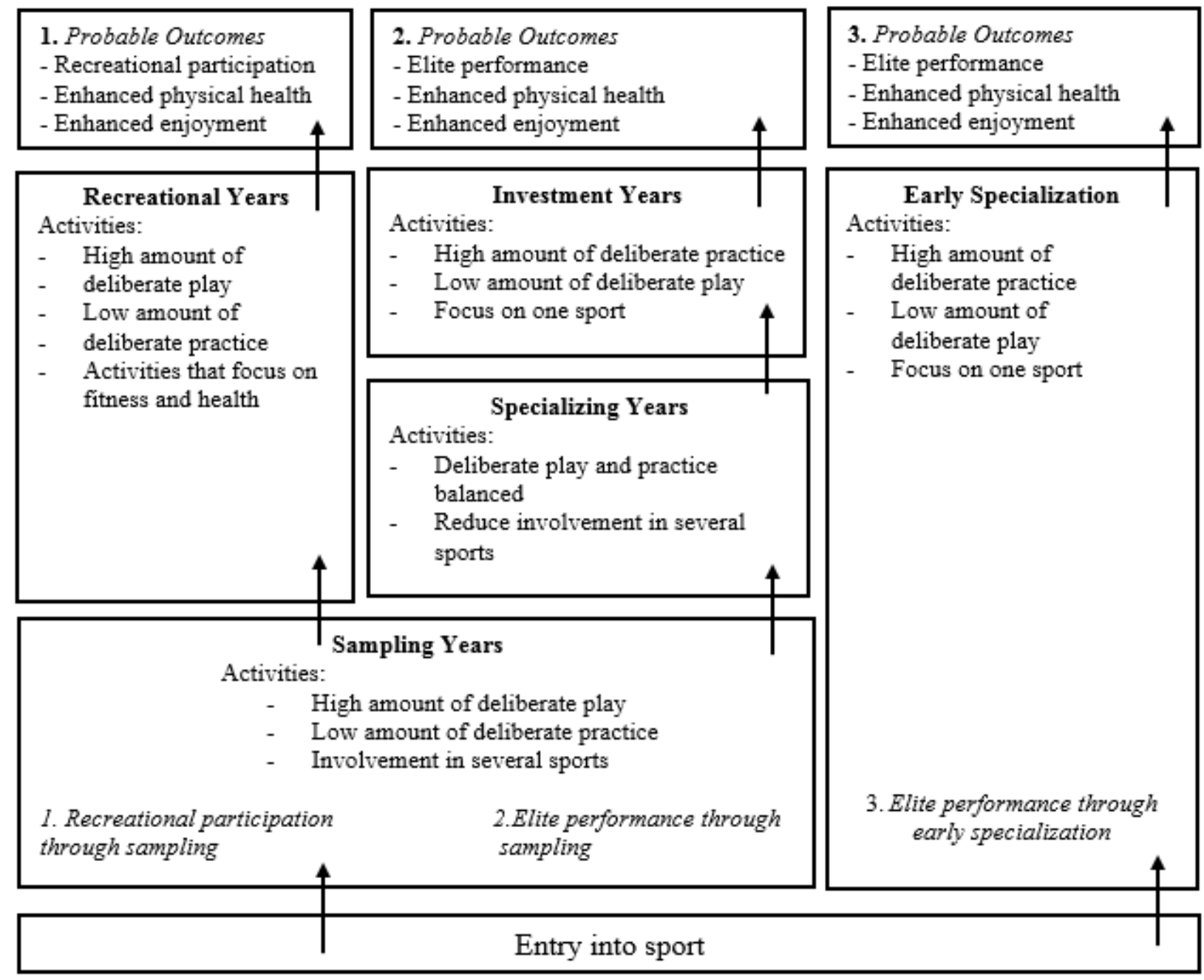

Figure 1. Developmental Model of Sport Participation. Adapted from Côté et al. (2007). 


\section{Appendix A}

Interview Guides

Participant Interview Guide

1. How old are you? How long have you participated in this archery class at the sport complex? How long have you participated in archery?

2. Tell me what you like to do at school? Tell me what you like to do for fun?

3. Can you tell me about all the sports you play, on a team or just for fun? Are there any other sports you play, on a team or just for fun? Can you tell me more about ? How often do you play each sport?

4. What other sports would you like to play? How come you don't play How did you choose these sports?

5. How does your family support/help you playing ? Do your parents want you to play___ ? Did your parents help you decide which sports to play? Come to games? Practice? Do you parents play sports? Did they in the past?

6. How does school affect you playing ? Do you think playing sports affects your school?

7. Do you have a coach? Tell me more about your coach. What do you like about your coach?

8. Do you practice for any sports? Can you tell me about a typical practice? On your own? With a team? Do you like practicing?

9. Have you ever stopped playing any sports? How did you decide to stop? Did you want to stop? Are you glad you stopped?

10. How long do you think you will play each sport? How far do you want to go? Do you want to become a professional athlete or do you just want to play for fun? Olympics?

Parent Interview Guide

1. How many children do you have in the sport of archery? How many children are in your home? Can tell me about yourself?

2. Tell me about your son or daughter/family?

3. Can you tell me about the sports you currently play or have in the past? Archery?

4. Can you tell me about the things your son or daughter does for physical activity/fun?

5. Can you tell me about the sports your son or daughter plays? How did he/she choose these sports? Practice? How? Compete? How?

6. How long has your son or daughter been playing ? How long do you think he/she will play ? Do you think he/she will can make a career out of or gain a scholarship?

7. Tell me about your involvement in your son or daughter's sports? Did you help them choose a particular sport? Did you help them quit a sport?

8. Can you tell me your thoughts about archery? Perception? Involvement? 